\title{
Movimentos sociais e democracia: a tensão necessária
}

\author{
= \\ Marcus Abilio Pereira \\ Departamento de Ciência Política \\ Universidade Federal de Minas Gerais
}

\begin{abstract}
Resumo: $O$ presente artigo analisa algumas das críticas feitas às teorias deliberativas da democracia, de forma a resgatar o conflito como componente determinante para o desenvolvimento das democracias contemporâneas. Esta paisagem teórica permitiu um avanço em relação às questões da inclusão política, ao reconhecer a importância da autonomia política e ampliação da igualdade formal. Apesar destes avanços, as teorias deliberativas da democracia passaram a ser objeto de críticas em relação à excessiva ênfase no consenso, o que acabou por eclipsar outras formas de ação política, tais como as ações coletivas de conflito. Neste artigo, busco reforçar a importância da ênfase no conflito como elemento determinante para o desenvolvimento de nossas democracias. Para tanto, promovo um diálogo entre a teoria deliberativa da democracia e a teoria dos processos políticos, que tem como foco central a análise da relação entre os atores coletivos, suas políticas de conflito e o contexto político.
\end{abstract}

Palavras-chave: teorias deliberativas da democracia; consenso; conflito; participação política; movimentos sociais

\begin{abstract}
This paper analyses some of the critics that were directed to the theories of deliberative democracy, in order to rescue the idea of conflict as a crucial component for the development of contemporary democracies. These theories have contributed to a theoretical breakthrough on the issues of political inclusion, recognizing the importance of political autonomy and expansion of formal equality. Despite these advances, theories of deliberative democracy have become the object of criticism in the last decade, due to the excessive emphasis on consensus, which eventually eclipsed other forms of political action, such as contentious politics. In this paper I attempt to reinforce the idea of conflict as a decisive element for the development of our democracies. In this sense, I promote a dialogue between the theories of deliberative democracy and the theory of political processes, which has as it's central focus the analysis of the relationship among collective actors, contentious politics and the political context.
\end{abstract}

Keywords: theories of deliberative democracy; consensus; conflict; political participation; social movements 


\title{
Introdução ${ }^{1}$
}

\begin{abstract}
"A real democrat would have to go further and recognize that democracy can never be fully institutionalized. There can be no point in time at which one could relax and say that we have arrived at a perfect procedural institutionalization of the principles of democratic legitimacy. Like the principle of rights, democracy must be seen as a verité à faire, a learning process, no matter what institutional arrangement of the polity has been achieved. Every empirical organizational form of democracy has its exclusionary mechanisms" (COHEN and ARATO, 1992).
\end{abstract}

A partir da década de 1980 temos o que Dryzek (2000) define como a "virada deliberativa" da teoria democrática, que procura resgatar os componentes da deliberação racional dos cidadãos dentro do processo político. Esta corrente teórica permitiu um avanço em relação às questões da inclusão política, ao reconhecerem a importância da autonomia política e da ampliação da igualdade formal. Apesar destes avanços, as teorias deliberativas da democracia passaram a ser objeto de críticas de diferentes correntes de pensamento. Entre as diferentes críticas, destaca-se a percepção de que a excessiva ênfase no consenso acabou por eclipsar outras formas de ação política que vão além da participação cidadã nos espaços de partilha decisória, espaços estes que colaborariam para um aprofundamento da democracia nas sociedades contemporâneas.

Neste artigo, busco reforçar a importância da recuperação do conflito como elemento determinante para o desenvolvimento de nossas democracias. Na perspectiva aqui adotada, o conflito não deve ser analisado na chave liberal das teorias democráticas, mas como um elemento constitutivo do debate público e meio de construção do interesse público.

Na primeira parte do artigo, recupero as principais críticas desenvolvidas no decorrer dos últimos anos acerca da real capacidade de inclusão de grupos historicamente excluídos, seja em função de um suposto elitismo cognitivo, da possível manipulação dos consensos produzidos, seja em função do próprio questionamento da teoria deliberativa da democracia como parte de uma teoria crítica. Em seguida, recupero a noção do conflito como elemento fundamental dos processos políticos, através do reconhecimento de uma tensão necessária entre movimentos sociais e democracia. Na última parte, busco uma aproximação entre teoria democrática e teoria dos movimentos sociais através da apropriação da teoria dos processos políticos, que tem como foco principal a análise da relação entre os atores da ação coletiva e o contexto político institucional. Neste sentido, procuro enfatizar o protesto como um recurso político que permite a explicitação de um conflito que possa estar encoberto por diferentes mecanismos, incluídos os processos deliberativos. Na conclusão, reafirmo a importância de analisarmos não só os processos deliberativos e questioná-los, mas também a necessidade de focarmos nossas análises nos movimentos sociais que, por motivos diversos, não podem ou não querem participar

\footnotetext{
1 Gostaria de agradecer aos comentários, críticas e sugestões dos professores Ricardo Fabrino (UFMG) e Gabriel Feltran (UFSCAR).
} 
dos espaços de partilha decisória, e desenvolvem repertórios de ação direta com o objetivo de manter uma tensão contínua dentro das democracias contemporâneas.

\section{Críticas à teoria deliberativa da democracia}

A temática "deliberação" entrou, paulatinamente, na ordem do dia das discussões sobre a democracia a partir do século passado. A democracia deliberativa, vista como uma inovação dentro da teoria democrática, buscou resgatar a já desgastada democracia representativa que teria se tornado incapaz, dentro do marco da agregação, de responder às expectativas dos cidadãos contemporâneos em sociedades pluralistas. A baixa participação eleitoral, a desmobilização partidária, a diminuição do número de associações e da participação voluntária serviriam de elementos para sustentar o argumento da crise da democracia representativa².

Apesar de quase todos os teóricos democráticos hoje em dia defenderem algum modo de deliberação como forma de aumentar a legitimidade do sistema democrático, a teoria deliberativa tem sido objeto de críticas e de novas propostas em relação aos seus pressupostos teóricos. Nesta primeira parte, desenvolvo três conjuntos de críticas a esta corrente teórica relacionados à produção do consenso como forma de participação limitante, o caráter elitista dos pressupostos deliberativos e o questionamento da teoria deliberativa da democracia como uma teoria crítica.

\section{A produção do consenso como forma de participação limitante}

O questionamento da possibilidade de produção de consensos dentro da teoria democrática deliberativa se dá através da análise da dinâmica deliberativa. Sunstein (2003) analisa a possibilidade de ocorrer uma polarização das posições distintas dentro dos processos deliberativos; Elster (1998) e Shapiro (2003) questionam a qualidade das decisões produzidas; Stokes (1998), Przeworski (1998) discutem a possibilidade de manipulação e de erro de avaliação das propostas por parte de seus participantes; por último, Santos et al (2004, p.71) analisam a imposição de uma agenda, dos procedimentos e dos critérios de seleção e participação pelos atores dominantes.

Sunstein (2003) questiona a possibilidade da produção de consensos dentro do processo deliberativo em função da tendência a uma polarização entre grupos heterogêneos. Segundo o autor, o caminho que pode levar a essa polarização passa pela necessidade que o indivíduo tem de reconhecimento de pertencimento social a um determinado grupo de forma a manter sua reputação. Tendencialmente, segundo o autor, os indivíduos procurarão sustentar suas posições antagônicas se estiverem em grupos distintos, mantendo assim suas lealdades de grupo, reforçando seus pertencimentos através de participações que intuitivamente possam convencer e reforçar os argumentos dos grupos do qual fazem parte. Um segundo ponto relevante é o questionamento do que o autor vai chamar de like-minded people, onde o conjunto de questões que são consideradas como relevantes por

2 É importante ressaltar que não existe uma unanimidade em relação a estes argumentos. Para uma visão contrária, conferir NORRIS (2002). 
aqueles que estão deliberando é partilhado à partida. Apenas para exemplificar, um grupo de skinheads que se encontrem regularmente em um site na internet ou em um espaço qualquer para deliberar sobre a importância da manutenção de posturas racistas e homofóbicas e as melhores táticas para promoverem ataques a minorias não ajuda em nada o processo de fortalecimento democrático. Dadas estas condições, estaríamos sujeitos ao insulamento destes grupos, que poderia levar à fragmentação social $^{3}$. Outro ponto relevante levantado pelo autor é a importância que é dada às participações de indivíduos de origens distintas, sejam elas componentes étnicas, de gênero ou de classe social. Sunstein argumenta que indivíduos com status sociais elevados tendem a ser mais ouvidos e suas posições consideradas mais relevantes do que as tomadas por indivíduos que sejam de quaisquer minorias. Mais ainda, os indivíduos com baixo status social sofreriam de uma síndrome de baixa confiança e teriam receio de se manifestar temendo alguma forma de represália (SUNSTEIN, 2003, p.94).

Shapiro levanta também algumas questões sobre o processo deliberativo que considero relevantes: qual deve ser a quantidade necessária de deliberação para tomarmos uma decisão? Que tipo de deliberação é melhor? (SHAPIRO, 2003, p.121). A crítica se relaciona a um dos pressupostos fundamentais da teoria deliberativa. $O$ autor sustenta que aqueles que defendem os benefícios da deliberação "take a neo-Hegelian philosophical psychology for granted, according to which a kind of intersubjective recognition is the highest stage of being" (SHAPIRO, 2003, p.127). Shapiro sustenta que não há nada que possa justificar o privilégio dado a esta visão da condição humana sobre outras tantas. É exatamente este ponto que permitirá ao autor questionar todo o processo deliberativo, pois, em contraponto à visão neo-hegeliana, ele considera que as relações humanas são conflitivas e estes conflitos estão espalhados por todas as esferas da sociedade, tendo a política a função de lidar com este componente humano. A inevitabilidade do conflito levaria a posturas distintas daquelas defendidas pelos teóricos deliberativos e não há nada que possa garantir que os participantes destes processos estejam dispostos a produzir consensos, pois estes poderão ser vistos como opressivos. Para além disso, mesmo que os indivíduos tenham esta disposição, não há, segundo o autor, nenhuma razão para acreditarmos que a deliberação irá proporcionar a produção de consensos. Aqui vemos claramente a conexão do argumento de Shapiro com o argumento de Sunstein desenvolvido anterioromente. Como afirma Sunstein, a possibilidade de uma polarização dentro do processo deliberativo deve ser levada em conta seriamente.

Por outro lado, o ponto fundamental da crítica de Stokes (1998) sobre os processos deliberativos se baseia em sua análise das preferências e identidades dos cidadãos em ambientes democráticos. Para tanto, a autora faz uma distinção entre identidades e pseudoidentidades. Segundo ela, não somente as preferências podem ser alteradas em processos comunicativos, mas também as identidades. Partidos políticos e Estados procuram moldá-las de acordo com suas orientações políticas de forma a alcançarem legitimidade e apoio às suas propostas políticas. As pseudoidentidades podem ser construídas a partir de enquadramentos (frames) que na verdade são prejudiciais aos próprios indivíduos que delas se apropriam. Em processos deliberativos, portanto, identidades poderão ser construídas de forma a prejudicarem aqueles que deles fazem parte, encobrindo reais interesses que

\footnotetext{
${ }^{3}$ No seu livro Republic.com, o autor vai oferecer vários exemplos desta situação.
} 
Ihes são desfavoráveis. Segundo Stokes, a deliberação pode permitir que políticas sejam direcionadas a interesses específicos através da manipulação das preferências dos cidadãos (STOKES, 1998, p.135).

Por sua vez, o projeto de Santos et al (2004) pelo reconhecimento da diversidade epistemológica do mundo em contraponto à imposição do cânone científico ocidental procura questionar como as formas de participação "democrática" podem encobrir relações desiguais entre os participantes. Segundo os autores, uma forma de participação limitante pode se manifestar de diferentes maneiras, umas mais sutis, outras explícitas, mas todas com o intuito de legitimar as decisões políticas tomadas com um "verniz" democrático.

O ponto fundamental para esta discussão é a imposição da busca de um consenso, mesmo que isto signifique a secundarização da controvérsia, elemento fundamental para a democracia. A imposição da participação em determinados fóruns participativos ou deliberativos busca somente a legitimação do processo dito "democrático" e procura desqualificar outras formas de participação política, de mobilização e de ação coletiva, tais como passeatas, manifestos virtuais, greves, caminhadas, manifestações, desobediência civil, etc. Uma vez que os procedimentos muitas vezes não são realmente participativos ou deliberativos, temos, na verdade, um "consenso imposto", no qual diferentes formas de participação podem, assim, aparecer em versões que tendem a reforçar os modos hegemônicos de conhecimento e de exercício do poder político (SANTOS et al, 2004, p.71). Quando essas condições estão dadas devemos reconhecer, por fim, que "any consensus reached is accomplished through an evolving process of coercion and exclusion" (CROSSLEY, 2004, p.11)

Possíveis limitações decorrentes tanto dos diferentes status sociais dos indivíduos como da possibilidade de radicalização e insulamento de determinados grupos dentro do processo deliberativo não inviabilizariam, necessariamente, a deliberação, mas servem, sim, de avisos importantes na construção dos processos deliberativos, de tal forma que possamos desenvolver mecanismos que garantam a paridade entre indivíduos de diferentes backgrounds e que também inviabilizem as polarizações que possam vir a ocorrer. Por isso, devemos nos ater às formas organizativas dos processos deliberativos de modo a garantir uma participação igualitária e equitativa entre os diferentes participantes, independentemente de suas condições socioeconômicas.

\section{Pressupostos deliberativos ou elitismo cognitivo?}

Em sua discussão sobre os requisitos necessários para uma efetiva participação em processos deliberativos, Bohman (1997) afirma a necessidade de igualdade em dois sentidos para que tenhamos decisões legítimas: primeiro, a igualdade entre os cidadãos e, segundo, que suas razões devam ser consideradas igualmente. Mas em contextos nos quais grupos sociais sofrem preconceito em razão de sua etnia, raça, gênero, opção sexual e religião, como podemos pensar que suas respectivas razões, propostas e demandas sejam igualmente consideradas em processos deliberativos? Segundo o autor: 
"Deliberative democracy should not reward those groups who simply are better situated to get what they want by public and discursive means; its standard of political equality cannot endorse any kind of cognitive elitism ${ }^{4}$. (..) The most basic measure of equality must consider the differences in the capabilities of agents to convert resources into the means to achieve their goals" (BOHMAN, 1997, p.332).

Este é o ponto de partida para uma importante crítica que é dirigida ao modelo habermasiano da democracia deliberativa, ou seja, a imposição de um modelo discursivo racional e o não reconhecimento de outras práticas comunicativas que também poderiam servir como mecanismos para colaborar no processo deliberativo de escolha coletiva (YOUNG, 2000, 2001; SANTOS, 2004; SANDERS, 1997; BOHMAN, 1997; CROSSLEY, 2004; DRYZEK, 2000; POLLETTA, 2006; CHAMBERS, 2003; KNIGHT and JOHNSON, 1997; FRASER, 1996). O núcleo deste conjunto de críticas a este modelo democrático baseia-se no questionamento da neutralidade dos processos deliberativos que, segundo estes autores, sistematicamente exclui um conjunto de atores sociais da participação efetiva na política democrática.

O confronto entre a teoria deliberativa da democracia com temas como a identidade, diversidade e reconhecimento tem colocado questões fundamentais para a ampliação das práticas comunicativas em processos deliberativos e tem questionado a incapacidade da proposta habermasiana em lidar com grupos sociais marginais que não conseguem cumprir os requisitos mínimos do discurso. De acordo com Chambers:

\footnotetext{
"Deliberative democracy has benefited from the "what about ..." line of argument. What about aboriginal peoples and their use of story telling and greeting, what about African Americans and their repertoire of meanings, what about the religious and their appeal to the faith, what about the oppressed and their appeal to anger and passion, what about...? This does not lead to ad hocism. It leads to a richer and more useful idea of public reason that addresses the real-world challenges. (...). The intersection between deliberative theory and diversity theory is becoming less an intersection and more a merger" (CHAMBERS, 2003, p.322).
}

Young $(2000,2001)$ distingue duas formas de exclusão nos processos de discussão política e de tomada de decisão. A primeira, exclusão externa, está relacionada ao impedimento de determinados grupos ou indivíduos de participar destes processos; a segunda, exclusão interna, está relacionada à exclusão dentro destes mesmos processos, através de mecanismos como a definição de temáticas que não são partilhadas por todos e a definição de certas formas de comunicação como as únicas possíveis. Desta forma, "privileging reasoned discourse comes at the expense of another deliberative standard, that of equality" (POLLETTA, 2006, p.702)

Assim como Young, Sanders procura sustentar em sua crítica o caráter excludente da participação política dentro de determinadas construções deliberativas. A autora afirma que, da mesma 
forma como os elitistas restringiram a participação ao defenderem a necessidade das decisões serem tomadas por especialistas e uma postura moderada (que não seria uma característica das 'massas'), os teóricos deliberativos acabam por excluir grande parte dos indivíduos quando demandam uma participação racional, contida e orientada (SANDERS, 1997, p.370). Para além disto, a autora reafirma também o perigo do preconceito em espaços deliberativos, pois mesmo que questões como renda e escolaridade sejam resolvidas, indivíduos ou grupos de indivíduos terão suas intervenções mais ou menos valorizadas do que outros em função de questões relacionadas a raça, classe e gênero (SANDERS, 1997).

Por último, Santos et al (2004) questionam a hierarquização de conhecimentos e competências distintas, fruto de processos coloniais europeus e que se justificavam numa "capacidade superior de conhecer e de transformar o mundo, ausente na ciência" (SANTOS et al, 2004, p.20). A transformação epistemológica que ocorreu no século XIX e sua capacidade de "destruição criadora" gerou dois processos paralelos: o primeiro, de desqualificação de outras formas de conhecimento, levadas para as margens das teorias dominantes; o segundo processo foi o epistemicídio que, ao destruir outras formas de conhecimento concorrentes à produção hegemônica, levou à subalternização de grupos sociais que assentavam suas percepções de mundo e práticas nestes mesmos conhecimentos. Os pressupostos habermasianos da racionalidade comunicativa poderiam ser utilizados para legitimar esta hierarquização das formas de conhecimento, desqualificando outras formas comunicativas não ocidentais, denominadas "não científicas", ou "não especializadas".

Com estas críticas é possível perceber claramente que a imposição de um modelo discursivo racional limita as possibilidades de participação de muitos cidadãos, restringindo-a a uma minoria, sem contar que inviabiliza a utilização deste modelo deliberativo em países que não tenham uma tradição ocidental e que não tenham passado pelo processo de modernização preconizado por Habermas. Tornase necessário, portanto, romper com esta imposição que acaba por levar uma proposta, a princípio inclusiva, a tornar-se discretamente excludente.

\section{Teoria deliberativa da democracia - ainda uma teoria crítica?}

O último conjunto de críticas dirigidas à proposta habermasiana da democracia deliberativa versa sobre a tentativa de articulação dos preceitos do Estado de direito liberal com os pressupostos democráticos. Esta tentativa de articulação levaria à diminuição do potencial transformativo das práticas democráticas, dificultando assim o aprofundamento democrático. Dryzek (2002, 2005) e Mouffe (2000) são dois dos principais críticos desta aproximação excessiva entre os preceitos do liberalismo constitucional e a proposta deliberativa.

Dryzek (2002, 2005) questiona a excessiva aproximação de Habermas e seu modelo democrático deliberativo com os preceitos liberais. Segundo o autor, a proposta democrática deliberativa teve duas fontes fundamentais - o constitucionalismo liberal e a teoria crítica - e, apesar das diferenças existentes entre estas duas paisagens teóricas, infelizmente, segundo o autor, a aproximação entre ambas tem ocorrido às custas da componente crítica da teoria deliberativa democrática. 
São duas as diferenças que o autor aponta entre as propostas liberal e crítica da democracia. As duas reconhecem a comunicação livre de distorções como elemento-chave da proposta deliberativa. Para alcançar tal situação, os liberais se prendem a arranjos constitucionais e legais para lidar com as distorções e não avançam em relação ao reconhecimento de outros agentes de distorção da comunicação que não poderão ser combatidos através dos mecanismos do Estado de direito. Os teóricos críticos não somente reconhecem estes agentes de distorção como também propõem mecanismos para lidar com os mesmos. A segunda diferença se relaciona à percepção dos teóricos críticos de que a participação democrática é capaz de modificar os indivíduos através do caráter didático da democracia. Os teóricos liberais se baseiam em premissas de que os indivíduos não se modificam durante o processo participativo, pois possuem preferências que estão dadas (DRYZEK, 2002, p.21). Habermas é um exemplo claro desta aproximação. Ao descrever a racionalidade comunicativa e suas consequências para a política deliberativa, Dryzek afirma que:

\footnotetext{
"Decision is ideally secured by consensus; implementation of the decision is secured only by the commitment of the individuals involved to the content of that consensus; and subsequent compliance relies on free consent. Such a sequence is not easily related to realworld political institutions and processes, especially those in complex and plural societies" (DRYZEK, 2002, p.24).
}

Em sua formulação da teoria deliberativa da democracia, Habermas passa a aceitar, primeiramente, as estruturas políticas e econômicas como dadas; em segundo, aceita também elementos do sistema político liberal, tais como as eleições, o poder normativo do legislativo e a estrutura administrativa para implementá-lo. Em sua construção teórica, a possibilidade de crítica por parte de grupos sociais marginalizados de tais estruturas ocorre através da influência que fluxos comunicativos, oriundos da esfera pública, exercem sobre o sistema político-administrativo. As associações da sociedade civil absorvem as demandas e temas da sociedade privada e procuram amplificá-los para a esfera pública. Segundo Dryzek, Habermas não dedica a devida atenção aos agentes extraconstitutionais que promovem tanto a distorção quanto a influência democrática, tais como protestos, demonstrações, boicotes, eventos midiáticos, lobbying e outros tantos (DRYZEK, 2002).

Por sua vez, a construção do argumento de Mouffe $^{5}$ tem como foco principal o conflito inevitável entre a democracia e o pluralismo liberal e a tentativa da corrente deliberativa em encontrar um equilíbrio entre ambos. Para a autora, tal equilíbrio é impossível de ser alcançado dados os pressupostos distintos em relação à noção de igualdade. Enquanto para o liberalismo a igualdade de todos seres humanos se baseia na ideia de uma humanidade, a igualdade da democracia se baseia na ideia de um 'demos'. No segundo caso, torna-se necessária a dicotomia nós-eles, incompatível com a proposta liberal de igualdade, que deveria incluir toda a humanidade. Mouffe, ao invés de aceitar tal argumento como uma contradição, prefere assumi-lo como uma lógica de conflito que não permite o

\footnotetext{
${ }^{5}$ Para uma crítica da democracia agonística de Mouffe, vide Drizek (2005).
} 
alcance de um equilíbrio, sendo possíveis apenas precárias e temporárias negociações desta tensão entre os dois elementos (MOUFFE, 2000).

Nesta perspectiva, a legitimidade do sistema democrático se constrói a partir de procedimentos nos quais a participação de indivíduos se dará em condições de igualdade, onde todos terão oportunidade de se manifestar, além da possibilidade de questionamento dos próprios procedimentos e a possibilidade de inclusão de indivíduos que não faziam parte da deliberação. O problema fundamental que se coloca é como lidar com um dos pressupostos da igualdade democrática, que se baseia na noção nós-eles, quando um dos pressupostos da teoria habermasiana da situação ideal de fala é exatamente a construção de consensos sem exclusão de quem quer que seja. Esta questão se torna relevante quando pensamos em determinados grupos minoritários, seja em questões relacionadas ao gênero, etnia ou opções religiosas, que muitas vezes não participam dos debates deliberativos em função de preconceitos, ou, então, até participam, mas através da negação da sua própria diferença.

O caráter antagônico do político e o reconhecimento do elemento agonístico da política permitem que se enfatize o conflito como elemento fundamental dentro do aprofundamento democrático (MOUFFE, 2000). A excessiva ênfase dada pelos teóricos deliberativos da democracia no consenso e nos espaços de partilha de poder de deliberação e decisão, de certa forma, acabou por obscurecer outras formas de ação política, tais como manifestações, passeatas, abaixo-assinados, invasões e "cyberações" desenvolvidas por atores da sociedade civil.

A autora sustenta a impossibilidade de construção de consensos através de processos deliberativos em função do reconhecimento de um antagonismo inerente às relações humanas dentro do político, reconhecimento este que seria negado pelas proposições deliberativas da democracia. Segundo Mouffe, Habermas sustenta a possibilidade de se construírem consensos através de procedimentos, onde a situação ideal de fala eliminaria os interesses individuais que não poderiam ser aceitos do ponto de vista moral. Mas, como lida o autor com a pluralidade em nossas sociedades? Para Habermas, a separação entre ética e moral seria o elemento fundamental para a construção de consensos. No campo da ética estariam as questões em relação à boa vida, enquanto no campo da moralidade estaria a possibilidade de construção de procedimentos imparciais que levariam à formulação de princípios universais (MOUFFE, 2000). Desta forma, segundo Mouffe, Habermas procura restringir o espaço da política a fim de alcançar um consenso. As relações conflitivas e não passíveis de alcançar tal consenso (o campo da ética no caso habermasiano) estariam fora destes espaços de discussão. Somente através desta lógica o consenso poderia ser alcançado, mas às custas da negação de questões relevantes a serem tratadas nas sociedades pluralistas. Segundo a autora, esta postura

"Highlights the fact that the domain of politics - even when fundamental issues like justice or basic principles are concerned - is not a neutral terrain that could be insulated from the pluralism of values and where rational, universal solutions could be formulated" (MOUFFE, 2000, p.92). 
A questão analisada por Mouffe lhe permite sustentar o argumento de uma "democracia agonística" que tem como centro "a politics of identity and difference that contests any attempts to impose universal identities, including supposedly 'rational' and 'neutral' ones advanced by liberal political theorists" (DRYZEK, 2002, p.60).

Desta forma, a autora sustenta uma diferença entre o político (political) e a política (politics). 0 político estaria relacionado à dimensão do antagonismo inerente às relações humanas, enquanto a política estaria relacionada às práticas, discursos e instituições necessárias para organizar a sua coexistência, sendo esta, portanto, potencialmente conflitiva, porque afetada pela dimensão do político (MOUFFE, 2000, p.101). O ponto fundamental dessa diferenciação é o reconhecimento do antagonismo dentro do político e da noção nós-eles dentro da política, o que levaria à busca de uma acomodação desta diferenciação dentro da democracia pluralista. O que se percebe dentro da corrente da democracia deliberativa na busca pela legitimação de consensos que vinculariam a todos é a negação desta dimensão.

Nesta formulação, a relação entre nós-eles não deve ser construída a partir de uma percepção do 'eles' como inimigos, mas como adversários. Com esta proposta, a autora procura diferenciar antagonismo (onde se reconhece o papel de inimigo) de agonismo (onde temos o papel de adversário). Desta forma, um adversário é "one with whom we have some common ground because we have a shared adhesion to the ethico-political principles of liberal democracy: liberty and equality" (MOUFFE, 2000, p.102).

Mouffe demarca assim sua diferença em relação à democracia deliberativa ortodoxa, que se baseia somente na racionalidade comunicativa, através do reconhecimento das "paixões" como um dos elementos presentes na esfera pública. Estas "paixões" seriam o reflexo dos antagonismos irreconciliáveis existentes no político, e que, portanto, devem ser reconhecidas dentro da esfera da política de forma a angariar legitimidade para as instituições democráticas. A negação de tal dimensão é que permitiria a Habermas sustentar uma esfera pública sem relações de poder e baseada somente na racionalidade. Somente assim o consenso poderia ser alcançado, na negação de que este só pode ser fruto de uma estabilização do poder exercido por determinados indivíduos, e que sempre estará produzindo algum tipo de exclusão. Segundo a autora, "consensus in a liberal-democratic society is - and will always be - the expression of a hegemony and the crystallization of power relations" (MOUFFE, 2000, p.49). A violência, nas suas dimensões de hostilidade e antagonismo, é parte constitutiva do político. Assim, reconhecer tais questões é fundamental para a construção de uma democracia que seja capaz de lidar com sociedades plurais, onde as desigualdades estão presentes e onde grupos minoritários tentam se fazer visíveis ao tematizar novas questões na esfera pública6.

Mais ainda, o reconhecimento de que quaisquer consensos produzidos serão sempre fruto de uma imposição hegemônica de determinados grupos cria uma situação de eterna insatisfação e luta dentro das sociedades contemporâneas, visto que sempre existirá algum 'nós' que estará subjulgando

\footnotetext{
6 Apesar de levantar questões relevantes em relação à deliberação, é interessante observar que a sua proposta de uma democracia agonística não vai além de meros preceitos gerais, não sendo capaz de oferecer nenhuma proposta para acomodar este antagonismo através de decisões coletivas (DRYZEK, 2005, p.221).
} 
algum 'eles' dentro do processo político. Desta forma, este argumento acabaria por inviabilizar a própria ideia de democracia.

É importante observar que as capacidades de adaptação e de apropriação de formas participativas pelo projeto hegemônico liberal são enormes. Mesmo com estes avanços participativos em espaços semi-institucionais, o perigo de cooptação e de apropriação desta ideia pelo projeto hegemônico neoliberal poderá levar à desqualificação de outras formas de participação. Isto porque a participação é vista, em alguns casos, como uma obrigação a cumprir por parte dos movimentos sociais, que receiam perder sua legitimidade para outros tipos de intervenção, tais como o protesto (SANTOS et al, 2004).

Com a abertura e o desenvolvimento dos espaços de partilha de poder deliberativo e decisório entre Estado e sociedade civil, o perigo que se corre é a completa desqualificação de outras formas participativas. Formas de protesto e demonstração podem ser contestadas como incivis, desordeiras e violentas por seus detratores. Mesmo assim, para Young, "disorderliness is an important tool of critical communication aimed at calling attention to the unreasonableness of others" (YOUNG, 2000, p.48).

Isto posto, o desafio que se coloca para além da criação de espaços de partilha de poder decisório é o fortalecimento dos atores da sociedade civil (movimentos sociais, associações, ONGs) e o desenvolvimento de outras formas de ação política, mais especificamente as ações diretas, que também explicitarão determinadas divergências e disputas entre grupos que não são capazes nem mesmo de adentrar nos processos deliberativos. Por isto, organizações e militantes que busquem promover a justiça devem se envolver tanto em ações de protesto e ações diretas quanto em processos deliberativos de partilha decisória, pois "a melhor ação prática e construção teórica da democracia será aquela que sustente ambas as ações e seja capaz de reconhecer a tensão entre elas" (YOUNG, 2003, p.119)

É importante reforçar que todas as críticas até aqui desenvolvidas não eliminam a possibilidade de apropriação de alguns dos conceitos produzidos pela teoria democrática deliberativa. Reconhecer a impossibilidade, segundo Mouffe, ou a dificuldade (defendida por Sunstein) da produção de um consenso a partir de procedimentos igualitários, não coercitivos e inclusivos não nos leva necessariamente a negar as possibilidades de um projeto emancipatório da modernidade e muito menos a capacidade de atores sociais excluídos lutarem por reconhecimento. As críticas levantadas servem de instrumento para ampliarmos a noção do político, reconhecendo o espaço para o dissenso e para a violência, dimensões estas inerentes à sociabilidade. Outra colaboração importante da autora para a discussão é o reconhecimento das desigualdades dentro da deliberação. Quão iguais podem e devem ser os indivíduos dentro de uma deliberação? Esta pergunta só é possível graças ao reconhecimento das desigualdades entre diferentes grupos sociais, onde muitas vezes grupos marginalizados têm dificuldade de minimamente cumprirem os requisitos básicos para a deliberação (CHAMBERS, 2003).

Ao assumir a relevância de algumas das questões colocadas por Mouffe e Dryzek neste debate, não tenciono colocar por terra toda a formulação teórica sobre a democracia deliberativa, muito pelo contrário, acredito que com estes insights posso, sim, desenvolver uma atitude de suspeição em relação aos consensos produzidos na esfera pública. Identificando problemas na produção dos consensos através da construção de hegemonias que ocorrem em função da exclusão de determinados grupos (seja em função do gênero, da etnia, das opções religiosas e outros) e o reconhecimento de outras formas comunicativas para além dos pressupostos discursivos habermasianos da racionalidade, assumo o 
antagonismo do político e recoloco o conflito como elemento central dentro da teoria democrática, tendo os movimentos sociais que optam por não adentrar nos espaços de partilha decisória o papel principal na manutenção de uma tensão necessária entre democracia e movimentos através do conflito.

\title{
Movimentos sociais e democracia - a tensão necessária
}

\begin{abstract}
"Just as a movement that is democratic but without internal conflict sacrifices political creativity to stability, so a democracy without movements would foreclose critical avenues of progressive change" (POLLETTA, 2002).
\end{abstract}

O papel dos movimentos sociais contemporâneos é promover a democratização das relações sociais dentro da sociedade civil, através da redefinição de papéis, normas, identidades (individuais e coletivas), conteúdo e modos de interpretação de discursos existentes nesta esfera. Desta forma, o desenvolvimento de políticas de inclusão - novos atores sociais reconhecidos como legítimos representantes dentro da sociedade política - e políticas de influência - através da mudança nos discursos políticos, de forma a levarem em conta novas identidades, necessidades, interpretações e normas - é fundamental para este projeto de sociedade civil democratizada (COHEN e ARATO, 1992, p.526). Um dos principais objetivos dos movimentos sociais tem sido o desenvolvimento de uma nova concepção de democracia. De acordo com Della Porta e Diani:

\footnotetext{
"In fact, it has been claimed that social movements do not limit themselves to developing special channels of access for themselves but that, more or less explicitly, they expound a fundamental critique of conventional politics thus shifting their endeavours from politics to metapolitics. From this point of view, social movements affirm the legitimacy (if not the primacy) of alternatives to parliamentary democracy, criticizing both liberal democracy and the organized democracy of the political parties" (DELLA PORTA and DIANI, 2006, p.239).
}

Dentro de um contexto democrático, a explicitação do conflito permite que determinadas temáticas adentrem o espaço público através do uso estratégico da mídia e da influência da opinião pública. Desta forma, os movimentos sociais influenciam e são influenciados pelos contextos políticos nos quais estão inseridos. Eles podem demandar a mudança ou a manutenção do ambiente em que estão inseridos; podem também questionar a forma pela qual as decisões políticas são tomadas, demandando uma maior participação popular nos campos decisórios. Mas a conexão entre democracia e movimentos sociais não é assim tão linearmente positiva. Segundo Giugni:

"However, nothing assures us that movements always make society more democratic, and this is true also for the so-called left-libertarian movements that have dominated the unconventional political arena during the last few decades. It would be wrong to proceed from a normative point of view that assumes that the contributions of social movements are 
"positive" in all circumstances. Such a point of view would mean mistaking reality for our desires and taking for granted something that must be demonstrated empirically" (GIUGNI, 1999).

Movimentos sociais também podem ser antidemocráticos, como atestam as experiências do entre-guerras na Europa onde o fascismo se desenvolveu, em parte, através da apropriação de estratégias de movimentos sociais e da organização de contramovimentos oriundos do receio que organizações pró-democracia provocaram em franjas conservadoras da sociedade (TILLY, 2004). Apesar destas constatações, Ibarra afirma que é evidente a influência recíproca de fortalecimento tanto da democracia quanto dos movimentos sociais (IBARRA, 2002).

A primeira relação causal entre o fortalecimento dos movimentos sociais e instituições democráticas pode ser pensada a partir da análise histórica do momento em que as eleições passaram a ser centrais dentro do processo político. Desde 1850, os processos eleitorais têm promovido os movimentos sociais de maneiras distintas. O alargamento dos espaços de discussão e de tematização de novas demandas promovidos pelos processos eleitorais permitiu o surgimento de movimentos sociais que buscavam ocupar este espaço para apoiarem determinados candidatos e projetos políticos. 0 reconhecimento da importância do número de apoiadores de determinados grupos políticos também possui um papel importante dentro da disputa democrática, permitindo um reconhecimento de futuros aliados ou opositores dentro do cálculo eleitoral. A ampliação de direitos tais como a manifestação e a organização durante os processos eleitorais também favoreceram o surgimento de movimentos sociais.

Os movimentos sociais também podem favorecer a democracia ao explicitarem a tensão inerente a qualquer decisão política. Esta tensão permite um aprofundamento e uma radicalização dos ideais democráticos de justiça, participação e inclusão de determinados grupos na luta pelo reconhecimento e a tematização de novas demandas até então não existentes ou silenciadas. A intensidade democrática aumenta à medida em que novos atores e demandas adentram o espaço público. Com o objetivo de analisar como os movimentos sociais podem favorecer a democracia, é necessário considerar algumas questões: primeiramente, quais as melhores estratégias para promover as mudanças sociais que levem a um aprofundamento democrático? Estratégias disruptivas ou moderadas? Se partirmos do princípio de que os movimentos sociais não possuem os recursos instituticionais para alcançarem os seus objetivos como os grupos de interesse e os partidos políticos, as ações disruptivas poderiam ser o melhor recurso que possuem, sejam elas ações violentas, greves ou manifestações. Isto do ponto de vista lógico aumenta consideravelmente a chance de alcançarem sucesso. Neste sentido, o contexto pode determinar um uso simultâneo ou sequencial dos dois tipos de ação política (SANTOS, 2005).

O contexto político dos movimentos também é um elemento relevante da análise, uma vez que em regimes muito fechados a via disruptiva pode levar a um aumento da repressão - como no caso dos movimentos de esquerda na América Latina durante os regimes autoritários, que acabaram por levar a um recrudescimento dos mesmos - enquanto em regimes fragilizados ou abertos à mudança a via disruptiva pode aumentar as chances de sucesso das ações dos movimentos. 
Outra questão relevante é saber se a dinâmica interna dos movimentos pode favorecer a democracia e suas relações com outros atores políticos. Internamente, os movimentos sociais têm procurado desenvolver estruturas organizativas baseadas na participação (ao invés da delegação), na busca da construção de consensos (em contraponto ao voto majoritário), e redes horizontalizadas (em contraponto a hierarquias centralizadas) (DELLA PORTA e DIANI, 2006, p.243). Através da existência de uma cultura de práticas horizontalizadas e de estruturas reticulares, há uma intensificação e uma "exportação" de práticas democráticas para as redes às quais o movimento faz parte, permitindo assim uma partilha de poder e uma igualdade entre os participantes das redes. Esta cultura democrática pode, assim, contaminar os processos políticos nos quais o movimento social estiver presente.

Partindo do pressuposto de que parte dos movimentos sociais buscam desenvolver interna e externamente práticas mais horizontalizadas, construindo consensos e estruturas organizativas participativas, as conexões com os pressupostos das teorias deliberativas e seus críticos ficam claras. A importância dada à qualidade da comunicação nas teorias deliberativas e a ênfase no conflito proposta por seus críticos se materializa nas diferentes possibilidades de ativismo dos movimentos. Por isso, estas passam a ter uma importância fundamental, pois são o locus onde as questões estão sendo objeto de negociação, mas, ao mesmo tempo, não anulam a autonomia dos atores políticos manifesta pelo seu caráter conflitivo (MELUCCI, 1996, p.221).

Os movimentos sociais são, portanto, atores fundamentais na construção de espaços deliberativos de forma a manter uma postura crítica em relação às instituições públicas, procurando tematizar novas questões que serão analisadas e comparadas com as propostas já existentes, colaborando, assim, com o processo de aprofundamento democrático.

Outro ponto relevante que deve ser devidamente analisado dentro das esferas públicas contemporâneas é o caráter heterogêneo da própria sociedade civil e a luta por espaço entre os atores sociais que dela fazem parte. Diferentes culturas e tradições políticas dos atores sociais demonstram que não existem apenas projetos democráticos em disputa. Projetos autoritários, populistas, neoliberais e outros também disputam espaços na esfera pública7. Temos, desta forma, dois eixos de conflito: por um lado, um eixo vertical entre o Estado e a sociedade civil; e por outro, um eixo horizontal entre diferentes atores da sociedade civil atuando na esfera pública.

Procura-se, assim, enfatizar o caráter conflitivo, tanto no seu eixo vertical (Estado-sociedade civil) quanto no horizontal (entre atores da sociedade civil), onde podem ser produzidos não apenas consensos, mas também falsos consensos, suscetíveis de hegemonia e exclusão. Para além desta relativização acerca da produção dos consensos, o espaço público torna-se um espaço em que outras formas de interação social tomam forma, através de dissensos ou através de ações violentas, e onde outras formas comunicativas também terão lugar.

\footnotetext{
7 Para um aprofundamento da discussão sobre a heterogeneidade da sociedade civil e a bad civil society, vide Chambers and Koptstein (2001).
} 


\section{As políticas de conflito}

Atualmente, as democracias existentes se veem confrontadas com a necessidade de aumentar a quantidade e a qualidade da participação de seus cidadãos, de reconhecer a existência de desigualdades sociais relacionadas a gênero, raça e etnia, e de reconhecer como legítimas as demandas dos movimentos sociais e organizações civis oriundas da esfera pública, de forma a aumentar a legitimidade do sistema político. Se pudéssemos resumir todas estas questões em uma pequena formulação, diríamos que devemos reconhecer e trazer de volta às nossas discussões teóricas o conflito.

Dentro das diferentes correntes teóricas dos movimentos sociais, a teoria dos processos políticos (TILLY, 1978; McADAM, 1982; TARROW, 1998) tem como foco central a análise da relação entre os atores da ação coletiva e o contexto político institucional. Para poder desenvolver este ponto específico, é necessário que se analise primeiramente a ideia de políticas de conflito (contentious politics), a fim de diferenciá-la de outras formas de ação coletiva. Políticas de conflito são:

\footnotetext{
"Episodic, public, collective interaction among makers of claims and their objects when (a) at least one government is a claimant, an object of claims, or a party to the claims and (b) the claims would, if realized, affect the interests of at least one of the claimants." (McADAM et al, 2001, p.5).
}

A principal diferença entre as ações coletivas de conflito e outras formas de ação coletiva, tais como a ação política institucional e o lobbying, é a capacidade que as primeiras têm em trazer para o centro da arena política indivíduos que a princípio não teriam acesso aos canais institucionais para alcançarem seus objetivos, e que, por isso, entram em conflito com as autoridades e as elites para consegui-los (TARROW, 1998). Mais ainda: através desta forma de ação política, cidadãos que participam de ações coletivas de conflito em alguns casos podem influenciar mais os responsáveis pelas decisões políticas do que os próprios eleitores (DELLA PORTA, 1999).

Os indivíduos que não possuem os canais institucionais buscam atuar coletivamente de forma a pressionar o sistema político através de diferentes formas de protesto, disruptivas ou não, violentas ou não, tais como greves, ocupações, passeatas, paralisações de trânsito, criações de vírus, invasões de sites, e etc. Estas formas de ação coletiva estão inscritas na história de um determinado movimento ou de uma determinada sociedade, sendo socialmente comunicadas, permitindo que rotinas específicas sejam seguidas cada vez que um movimento social se mobilize. Os líderes dos movimentos possuem a incumbência de inventar, adaptar e combinar diferentes formas de protesto que podem ser herdadas de outras mobilizações, realizadas separadamente ou em ações conjuntas com outras formas de protesto (TARROW, 1998, p.21).

As ações de protesto têm ganho força desde os anos 1980 (NORRIS, 2002; MELLUCCI, 1996; DELLA PORTA e DIANI, 1999; DELLA PORTA e TARROW, 2005; BENNETT, 2004), seja através de boicotes, demonstrações, invasões, e outras tantas formas criativas desenvolvidas pelas organizações de movimentos sociais (OMSs) e as organizações não governamentais (ONGs). De fato, as ações de protesto 
têm se tornado um meio de expressão política tão fundamental quanto a participação em partidos políticos, associações voluntárias e organizações comunitárias.

As diferentes formas de ação desenvolvidas por movimentos são fruto de um processo histórico cumulativo de atividades anteriormente desenvolvidas e que se adequam às necessidades e aos constrangimentos de cada processo específico que as entidades da sociedade civil desenvolvem, sejam eles constrangimentos financeiros, organizacionais, da agenda política, o nível de repressão política que podem estar sujeitos e as tecnologias que podem ser apropriadas.

De acordo com Tarrow, os repertórios de conflito são "at once a structural and a cultural concept, involving not only what people do when they are engaged in conflict with others but what they know how to do and what others expect them to do" (TARROW, 1998, p.30). Isto significa que os movimentos sociais possuem repertórios de ação que se modificam com o tempo, entre outras coisas, em função de mudanças tecnológicas que poderão ser apropriadas de formas distintas; em função do contexto político no qual estão inseridos e também em função das expectativas que outros atores sociais terão em relação às ações que irão tomar.

Nas sociedades contemporâneas baseadas na controle da informação, a intervenção para a manutenção do próprio sistema ocorre também nos domínios culturais e sociais, e não mais somente no sistema de produção material, pois, nestas sociedades, a produção está também baseada nas relações sociais, nos símbolos, nas identidades e nas necessidades individuais (MELUCCI, 1996, p.99).

Os conflitos inerentes a este modelo societário serão, portanto, baseados na luta pelos significados construídos por aparatos informacionais. Os movimentos sociais contemporâneos promovem uma luta pela possibilidade de construção e definição dos significados através de discursos públicos. Desta forma, os principais atores sociais nos conflitos em sociedades contemporâneas não são mais vinculados às classes das sociedades industriais, mas sim a grupos que defendem posições distintas em relação aos recursos cognitivos e simbólicos (MELUCCI, 2006, p.225).

Um dos possíveis caminhos para o aperfeiçoamento democrático é reforçar o caráter conflitivo entre os movimentos sociais e o sistema político. Através de ações na esfera pública, os movimentos sociais podem chamar a atenção da sociedade para determinadas temáticas, pressionando desta forma o sistema político a promover as mudanças ou manutenções de políticas que os primeiros considerem relevantes. As grandes manifestações populares contra a guerra do Iraque, as já icônicas "batalhas" de Seattle e Gênova, os Fóruns Sociais Mundiais ou Regionais que vêm ocorrendo em várias partes do mundo e as ocupações e passeatas do Movimento dos Sem Terra no Brasil são exemplos entre tantos outros desta segunda possibilidade.

\section{Conclusão}

Para compreendermos melhor os fenômenos de participação política nas sociedades contemporâneas, temos que reconhecer que nem todos os movimentos e associações estão dispostos a participar dos espaços institucionais e semi-institucionais de partilha de poder. Os motivos para a não. participação são diversos. Entre eles, existe o receio de cooptação e a discordância com os mecanismos 
desenvolvidos, que poderiam eventualmente definir a priori os temas a serem tratados e os procedimentos que levarão às decisões. Desta forma, muitos movimentos preferem manter distância em relação ao sistema político e agir independentemente no espaço público, utilizando a pressão sobre os atores políticos e a influência sobre a opinião pública como armas para alcançarem seus objetivos. Temos, portanto, posturas distintas de movimentos oriundos da sociedade civil: aqueles que veem no sistema político um possível parceiro na construção de mecanismos de participação e decisão; aqueles que mantêm uma postura independente em relação ao sistema político; e, por último, aqueles que podem se aproximar ou distanciar do sistema político em razão do contexto em que se encontram.

Se reconhecemos o conflito como elemento fundamental dos processos políticos e a democracia como a melhor forma para tratá-lo (DAGNINO et al, 2006, p.59), devemos reconhecer também o papel fundamental dos movimentos sociais na promoção de mudanças em certos aspectos da sociedade, através da tematização de novas demandas, do reconhecimento de desigualdades e pela manutenção de uma tensão contínua dentro das democracias, ao mesmo tempo em que colocam em xeque determinados processos e/ou decisões políticas, também colaboram no processo de canalização de tensões e expectativas em relação ao sistema político.

Os movimentos sociais são, desta forma, uma das principais formas de ação coletiva que permitem a articulação e a mobilização de coletividades em relação a diferentes demandas, através de diferentes repertórios de ação, tais como boicotes, manifestações públicas, passeatas nas ruas, invasões, abaixo-assinados e também, algumas vezes, o uso da violência. O protesto é um recurso político que permite a explicitação de um conflito que talvez estivesse encoberto por diferentes mecanismos. A falta de outros recursos institucionais de acesso às esferas de decisão política o transforma em um mecanismo de pressão e de publicização de uma temática que os atores excluídos destas esferas consideram relevante. A realização de ações inovadoras e/ou surpreendentes chama a atenção da mídia que irá influenciar a opinião pública, colocando em pauta uma temática relevante para os movimentos.

Portanto, para que se possa analisar a "saúde" de nossas democracias, torna-se necessário compreender a fundo as formas de ativismo político que estão sendo desenvolvidas. Os movimentos sociais contemporâneos representam uma diversidade enorme das novas formas de ativismo político e devem estar no centro das análises de novas práticas que representem uma alternativa a uma proposta totalizante e hegemônica de mundo.

\section{Referências Bibliográficas}

BENNET, W. L.; ENTMAN, R. M. Mediated Politics: A communication in the future of democracy. Massachusetts: MIT Press, 2003

BENNET, L. New media power: the Internet and global activism. In: COULDRY, N., CURRAN, J. (eds.). Contesting media power: alternative media in a networked world. Oxford: Rowman and Littlefield, 2003. 
Communicating global activism - strengths and vulnerabilities of networked politics. In: VAN de DONK, W.; LOADER, B.; NIXON, P.; RUCHT, D. (eds.). Cyberprotest: new media, citizens and social movements. London: Routledge, 2004.

BOHMAN, J. Public deliberation: pluralism, complexity and democracy. Cambridge: MIT Press, 1996.

Deliberative Democracy and effective social freedom: capabilities, resources, and opportunities. In: BOHMAN, J. and REGH, W. (eds.). Deliberative democracy: essays on reason and politics. Massachusetts: MIT Press, 1997.

CHAMBERS, S. "Deliberative Democratic Theory". Annual Review of Political Science, v. 6, p. 307-326, 2003.

CHAMBERS, S. and KOPSTEIN, J. "Bad Civil Society", Political Theory, v.29, n.6, p.838.866, 2001.

COHEN, J.; ARATO, A. Civil Society and Political Theory: Studies in Contemporary German Social Thought. Cambridge: MIT Press, 1992.

CROSSLEY, N. Making sense of social movements. Buckingham: Open University Press, 2002.

CROSSLEY, N.; ROBERTS, J. M. Introduction. In: CROSSLEY, N. and ROBERTS, J.M. (eds.). After Habermas: New Perspectives on the Public Sphere. Blackwell: Oxford/Malden, 2004.

DELLA PORTA, D.; DIANI, M. Social Movements: an introduction. Oxford: Blackwell Publishing, 2006 [1999].

DELLA PORTA, D.; TARROW, S. (eds.). Transnational protest and global activism. New York: Rowman and Littlefield Publishers, 2005.

DRYZEK, J.S. Deliberative democracy and beyond: liberals, critics, contestations. Oxford: Oxford University Press, 2002.

"Deliberative democracy in divided societies - alternatives to agonism and analgesia". Political Theory, v. 33, n. 2, p. 218.242, 2005.

ELSTER, J. (ed.). Deliberative Democracy. Cambridge: Cambridge University Press, 1998.

FISHKIN, J. S.; LASLETT, P. (eds.). Debating Deliberative Democracy. Oxford: Blackwell Publishing, 2003.

FRASER, N. Rethinking the public sphere: a contribution to the critique of actually existing democracy. In: CALHOUN, C. (ed.). Habermas and the public sphere. Cambridge: MIT Press, 1996.

GIUGNI, M.; McADAM, D.; TILLY, C. (eds.). How social movements matter. Minneapolis: University of Minnesota Press, 1999.

GIUGNI, M. Introduction: How social movements matter: past research, present problems, future developments In: GIUGNI, M.; McADAM, D.; TILLY, C. (eds.). How social movements matter. Minneapolis: University of Minnesota Press, 1999.

GUTTMAN, A.; THOMPSON, D. Deliberative Democracy Beyond Process In: FISHKIN, J.; LASLETT, P. (eds.). Debating deliberative democracy. Oxford: Blackwell Publishing, 2003.

HABERMAS, J. Three normative models of democracy, In: BENHABIB, S. (ed.). Democracy and difference: Contesting the boundaries of the political. Princeton: Princeton University Press, p. 21.30, 1996.

Direito e democracia: entre facticidade e validade. Rio de Janeiro: Tempo Brasileiro. v. 1. 2, 1997.

IBARRA, P. (Ed.). Social Movements and democracy. New York: Palgrave Macmillan, 2002.

KNIGHT, J. and JOHNSON, J. What sort of equality does deliberative democracy require? In: BOHMAN, J. and REGH, W. (eds.). Deliberative democracy: essays on reason and politics. Massachusetts: MIT Press, 1997.

McADAM, D. Political Process and the Development of Black Insurgency, 1930-1970. Chicago: The University of Chicago Press, 1982

McADAM, D., TARROW, S., TILLY, C. Dynamics of Contention. Cambridge: Cambridge University Press, 2001.

MELUCCI, A. Challenging codes: collective action in the information age. Cambridge: Cambridge University Press, 1996.

MOUFFE, C. The Democratic Paradox. London: Verso, 2000. 
NORRIS, P. Democratic Phoenix: Reinventing political activism. Cambridge: Cambridge University Press, 2002.

"Preaching to the converted? Pluralism, Participation and Party Websites". Party Politics - Special Issue: Party Politics on the Net. v. 9, n. 1, 2003.

POLLETTA, F. "Contending Stories: Narrative in social movements". Qualitative Sociology. v.21, n.4 p.419.446, 1998 Freedom is an endless meeting: democracy in American social movements. Chicago: The University of Chicago Press, 2002.

"Free spaces in collective action". Theory and Society, v. 28, n.1, p. 1.38, 1999.

POLLETTA, F.; LEE, J. "Is telling stories good for democracy? Rhetoric in public deliberation after 9/11". American Sociological Review, v. 71, n. 5, p. 699.723, 2006.

PRZEWORSKI, A. Deliberation and ideological domination. In: ELSTER, J. (ed.). Deliberative Democracy. Cambridge: Cambridge University Press, 1998.

SANDERS, L. M. “Against deliberation”. Political Theory, v. 25, n. 3, p. 347-376, 1997.

SANTOS, B. de S.; AVRITZER, L. Para ampliar o cânone democrático. In: SANTOS, B. de S. (ed.). Democratizar a democracia. Porto: Afrontamentos, 2003.

SANTOS, B. S., MENESES, M. P.; NUNES, J. A. Introdução: para ampliar o cânone da ciência: a diversidade epistemológica do mundo. In: SANTOS. B.S. (ed.) Semear outras soluções: os caminhos da biodiversidade e dos conhecimentos rivais. Porto: Edições Afrontamento, p. 19·101, 2004.

SANTOS, B.S. O Fórum social mundial: manual de uso. Porto: Edições Afrontamento, 2005.

SHAPIRO, I. Optimal Deliberation. In: FISHKIN, J.; LASLETT, P. (eds.). Debating deliberative democracy. Oxford: Blackwell Publishing, 2003.

STOKES, S. Pathologies of deliberation. In: ELSTER, J. (ed.). Deliberative Democracy. Cambridge: Cambridge University Press, 1998

SUNSTEIN, C. R. Republic.com. Princeton: Princeton University Press, 2001.

The law of group polarization In: FISHKIN, J.; LASLETT, P. (eds.). Debating deliberative democracy. Oxford: Blackwell Publishing, 2003.

TARROW, S. States and opportunities: the political structuring of social movement. In: McADAM, D., McCARTHY, J.D., ZALD, M.N. (eds.). Comparative perspectives on social movements: political opportunities, mobilizing structures, and cultural framings. Cambridge: Cambridge University Press, 1996. [1998].

Power in movement: social movements and contentious politics. Cambridge: Cambridge University Press, 2003

TARROW, S.; MEYER, D.S. The social movement society: contentious politics for a new century. New York: Rowman \& Littlefield, 1998.

TILLY, C. From mobilization to revolution. New York: McGraw·Hill Publishing Company, 1978.

The contentious French. Cambridge: The Belknap Press of Harvard University Press, 1986.

Popular Contention in Great Britain - 1758-1834. Cambridge: Harvard University Press, 1995.

Contention and democracy in Europe 1650-2000.Cambridge: Cambridge University Press, 2004.

YOUNG, I. M. Inclusion and democracy. New York: Oxford University Press, 2000.

Comunicação e o outro: além da democracia deliberativa. In: SOUSA, J. (org). Democracia hoje: novos desafios para a teoria democrática contemporânea. Brasília: Editora UnB, 2001. 

democracy. Oxford: Blackwell Publishing, 2003.

Marcus Abilio Pereira -marcusabilio@fafich.ufmg.br

Recebido para publicação em dezembro de 2010. Aprovado para publicação em agosto de 2011. 